\title{
Erratum to: Development and Verification of an Analytic Technique to Determine the Stiffness Parameters of Braided Tubular Parts
}

\author{
S. A. Samipour and Ya. S. Danilov" \\ Tupolev Kazan National Research Technical University, ul. Karla Marksa 10, Kazan, 420111 Russia \\ *e-mail:pla.kai@mail.ru \\ Received September 4, 2018
}

DOI: $10.3103 /$ S1068799818020253

The name of the first author of the article should be read as S.A. Samipour.

Affiliation of S.A. Samipour should be read as Tupolev Kazan National Research Technical University, ul. Karla Marksa 10, Kazan, 420111 Russia.

The original article can be found online at https://doi.org/10.3103/S1068799816040048. 